INOBIS: Jurnal Inovasi Bisnis dan Manajemen Indonesia

Volume 1, Nomor 4, September 2018

Andi Hendrawan; Aneu Yulianeu; Hari Sucahyawati; Indriyani

\title{
Pengembangan Kompetensi UMKM dengan Pembelajaran Organisasi
}

\author{
Andi Hendrawan \\ Mahasiswa Program Doktor Ilmu Manajemen UNSOED \\ Dosen Akademi Maritim Nusantara \\ Email: andihendrawan007@gmail.com \\ Aneu Yulianeu \\ Mahasiswa Program Doktor Ilmu Manajemen UNSOED \\ Dosen STMIK DCI Tasikmalaya \\ Email anjusu09@gmail.com \\ Hari Sucahyawati \\ Dosen Akademi Maritim Nusantara \\ Email harisucahyawati@yahoo.com \\ Indriyani \\ Dosen Akademi Maritim Nusantara \\ Email indrip2cd11010@gmail.com
}

\begin{abstract}
Abstrak
Pemberdayaan UMKM sangat strategis, karena potensinya yang besar dalam menggerakkan kegiatan ekonomi masyarakat, dan sekaligus menjadi tumpuan sumber pendapatan sebagian besar masyarakat dalam meningkatkan kesejahteraannya. Kompetensi UMKM meruapakan hal yang penting karena akan meningkatkan produktivitas dan kinerja UMKM. Peningkatan konpetensi UMKM salah satunya adalah dengan pembelajaran organisasi. Tujuan penelitian ini adalah untuk membuktikan pengaruh pembelajaran oragnisasi dalam meningkatkan kompetensi UMKM. Hasil mennjukan terdapat hubungan yang signifikan pengaruh pengaruh pembelajaran organisasi dalam meningkatkan komptensi UMKM. Hal mennjukan bahwa semakin baik pembelajaran oragnisasinya maka akan meningkatkan kompetensi UMKM.
\end{abstract}

Kata kunci: Komptensi, UMKM, Pembelajaran Organisasi

\section{Pendahuluan}

Sektor usaha kecil dan menengah memegang peranan yang sangat penting dalam membangun perekonomian masyarakat. Hal ini terutama bila dikaitkan dengan pemberdayaan ekonomi masyarakat dan jumlah tenaga kerja yang mampu diserap oleh usaha kecil dan menengah tersebut. Selain memiliki arti strategis bagi pembangunan, usaha kecil menengah juga berfungsi sebagai sarana untuk memeratakan hasil-hasil pembangunan yang telah dicapa (Lumbanraja P, 2017)

Pemberdayaan UKM sangat strategis, karena potensinya yang besar dalam menggerakkan kegiatan ekonomi masyarakat, dan sekaligus menjadi tumpuan sumber pendapatan sebagian besar masyarakat dalam meningkatkan kesejahteraannya. Pada tahun 2006, peran UKM terhadap 
INOBIS: Jurnal Inovasi Bisnis dan Manajemen Indonesia

Volume 1, Nomor 4, September 2018

\section{Andi Hendrawan; Aneu Yulianeu; Hari Sucahyawati; Indriyani}

penciptaan PDB nasional menurut harga berlaku tercatat sebesar Rp. 1.786,22 triliun (53,49\%), kontribusi usaha kecil tercatat sebesar Rp. 1.253,36 triliun $(37,53 \%)$ dan usaha menengah sebesar Rp. 532,86 triliun $(15,96 \%)$ dari total PDB nasional,

Dalam UU No.20/2008 tentang UMKM, didefinisikan bahwa pemberdayaan adalah upaya yang dilakukan Pemerintah, Pemerintah Daerah, Dunia Usaha, dan Masyarakat secara sinergis dalam bentuk penumbuhan iklim dan pengembangan usaha terhadap UMKM sehingga mampu tumbuh dan berkembang menjadi usaha yang tangguh dan mandiri. Prinsip pemberdayaan usaha mikro, kecil, dan menengah adalah: (a) Penumbuhan kemandirian, kebersamaan, dan kewirausahaan usaha mikro, kecil, dan menengah untuk berkarya dengan prakarsa sendiri. (b) Perwujudan kebijakan publik yang transparan, akuntabel, dan berkeadilan. (c) Pengembangan usaha berbasis potensi daerah dan berorientasi pasar sesuai dengan kompetensi Usaha Mikro, Kecil, dan Menengah. (d) Peningkatan daya saing usaha mikro, kecil, dan menengah dan kewirausahaan sangat besar peranannya di dalam perkembangan pertumbuhan ekonomi suatu Negara

Aaker(1993) menyatakan bahwa asset dan skill atau asset dan kompetensi merupakan instrument yang paling dasar untuk menghasilkan daya saing. Inovasi organisasi adalah penting bagi perusahaan untuk bersaing secara dinamis dengan lingkungan bisnis yang berkembang (Dooley and Sulivan, 2003), seperti diungkapkan oleh beberapa peneliti bahwa inovasi merupakan salah satu alat untuk mempertahankan pertumbuhan dan mencapai kinerja bisnis (Cottam et al, 2001),

Pengembangan ekonomi nasional di Indonesia, yang menjadi prioritas yaitu Usaha Mikro Kecil dan Menengah (UMKM). UMKM menjadi tulang punggung sistem ekonomi kerakyatan untuk mengurangi permasalahan kemiskinan dan pengembangannya mampu memperluas basis ekonomi serta dapat memberikan kontribusi yang signifikan dalam meningkatkan perekonomian daerah dan ketahanan ekonomi nasional. (Kurniawan,2011).

Pemberdayaan UMKM di tengah arus globalisasi dan tingginya persaingan membuat UMKM harus mampu menghadapi tantangan global, seperti meningkatkan inovasi produk dan jasa, pengembangan sumber daya manusia dan teknologi, serta perluasan area pemasaran. Hal ini perlu dilakukan untuk menambah nilai jual UMKM, utamanya agar dapat bersaing dengan produk produk asing yang kian membajiri sentra industri dan manufaktur di Indonesia, mengingat UMKM adalah sektor ekonomi yang mampu menyerap tenaga kerja terbesar di Indonesia (Sudaryanto 2011).

Hasil penelitian Ardiana,dkk. (2010) terkait pengembangan kompetensi SDM dan pengaruhnya terhadap kinerja UKM di Surabaya menemukan bahwa kompetensi SDM (pengetahuan, keterampilan dan kemampuan) berpengaruh terhadap kinerja perusahaan. Semakin tinggi kompetensi yang dimiliki oleh SDM UKM, akan semakin tinggi pula kinerja perusahaan. Penelitian serupa juga pernah dilakukan. Penelitian Sulistyandari dkk (2016) kompetensi SDM berpengaruh positif dan signifikan terhadap kinerja perusahaan. Hal ini berarti bahwa semakin tinggi kompetensi SDM akan semakin meningkatkan kinerja perusahaan yang ditunjukkan dengan semakin tingginya laba perusahaan.

George Freedman (1988) yang mengatakan bahwa suatu organisasi perlu mendukung adanya kegiatan inovasi, karena perusahaan yang menerapkan kegiatan inovasi memberi kesempatan pada anggota pemasar untuk menerapkan ide-ide baru dalam memasarkan produk, sehingga kegiatan inovasi marupakan salah satu kebijakan yang dilakukan perusahaan dalam memberikan arahan pada aktivitas inovasi. 
INOBIS: Jurnal Inovasi Bisnis dan Manajemen Indonesia

Volume 1, Nomor 4, September 2018

Andi Hendrawan; Aneu Yulianeu; Hari Sucahyawati; Indriyani

Banyaknya organisasi brilian yang mengalami kegagalan dan tidak dapat mempertahankan eksistensinya disebabkan karena organisasi-organisasi tersebut berhenti belajar dan tidak dapat menyesuaikan diri dengan perkembangan jaman dan teknologi. Untuk dapat terus mempertahankan eksistensi dan kinerja organisasi maka dibutuhkan sebuah proses pembelajaran organisasi. Proses pembelajaran dapat dicapai jika organisasi dapat memiliki kemampuan dalam berpikir dan bertindak secara lebih cepat dalam merespon setiap perubahan (Senge, 1990). Organisasi yang mampu melakukan proses pembelajaran tersebut dinamakan dengan organisasi pembelajar

Tujuan penelitian ini adalah untuk membuktikan apakah ada penegruh positif pemebelajaran organisasi terhadap pengembangan komptensi UMKM.

\section{Tinjauan Pustaka}

\section{Kompetensi Kewirausahaan}

Menurut Spencer dan Spencer (1993), kompetensi dibagi menjadi dua kategori, yaitu : treshold competencies dan differentiating competencies. treshold competencies adalah karakteristik utama yang harus dimiliki seseorang agar dapat melaksanakan pekerjaannya. Tetapi tidak untuk membedakan seseorang berkinerja tingg atau rata-rata. Sedangkan differentiating competencies merupakan faktor-faktor yang membedakan individu berkinerja tinggi dan rendah

Kompetensi kewirausahaan merupakan pengetahuan, sikap dan keterampilan yang terhubung satu dengan lainnya, yang diperlukan pengusaha untuk dilatih dan dikembangkan agar mampu menghasilkan kinerja terbaik dalam mengelola usahanya. Kompetensi yang harus dimiliki pengusaha adalah (Suryana, 2003):

1. Managerial skill. Wirausahawan harus mampu menjalankan fungsi perencanaan, pengorganisasian, penggerakkan dan pengawasan agar usaha yang dijalankannya dapat mencapai tujuan yang diinginkan. Ketrampilan ini merupakan syarat mutlak untuk menjadi wirausaha sukses.

2. Conceptual skill. Kemampuan untuk merumuskan tujuan, kebijakan dan strategi usaha merupakan landasan utama menuju wirausaha sukses. Pengusaha harus ekstra keras belajar dari berbagai sumber dan belajar dari pengalaman sendiri dan pengalaman orang lain dalam berwirausaha.

3. Human skill. Supel, mudah bergaul, simpati dan empati kepada orang lain adalah modal keterampilan yang sangat mendukung kita menuju keberhasilan usaha. Dengan keterampilan ini, pengusaha akan memiliki banyak peluang dalam merintis dan mengembangkan usahanya.

4. Decision making skill. Sebagai seorang wirausaha, seringkali dihadapkan pada kondisi ketidakpastian. Berbagai permasalahan biasanya bermunculan pada situasi seperti ini. Wirausaha dituntut untuk mampu menganalisis situasi dan merumuskan berbagai masalah untuk dicarikan berbagai alternatif pemecahannya.

5. Time managerial skill. Ketidakmampuan mengelola waktu membuat pekerjaan menjadi menumpuk atau tak kunjung selesai sehingga membuat jiwanya gundah dan tidak tenang. Keterampilan mengelola waktu dapat memperlancar pelaksanaan pekerjaan dan rencana yang telah digariskan. 
INOBIS: Jurnal Inovasi Bisnis dan Manajemen Indonesia

Volume 1, Nomor 4, September 2018

Andi Hendrawan; Aneu Yulianeu; Hari Sucahyawati; Indriyani

\section{Pemberlajaran Organisasi (Learning Organization)}

Berdasarkan Senge (1990), learning organization adalah organisasi dimana orang- orang secara berkelanjutan mengembangkan kapasitas mereka untuk mencapai hasil yang benar- benar mereka harapkan, dimana pola berpikir yang baru dipupuk, aspirasi bersama dibebaskan, dan orang- orang secara berkelanjutan belajar bagaimana belajar bersama.

Khandekar dan Sharma (2006) mengemukakan bahwa pembelajaran organisasi merupakan suatu proses untuk memperoleh pengetahuan, baik secara personal maupun secara kelompok yang berusaha diaplikasikan kedalam pekerjaan yang sedang mereka kerjakan berpengaruh terhadap kemampuan sebagai sumber keunggulan bersaing. Kualitas pembelajaran organisasi dapat didefiinisikan dengan sebagai tingkat baik/buruknya suatu pembelajaran di dalam organisasi yang diharapkan setiap anggotanya secara bersama-sama menerima dan mengumpulkan informasi dan ilmu pengetahuan yang sesuai kebutuhan dan kemampuan setiap individu, yang kemudian diinterpretasikannya dan bertindak sesuai interpretasi dari informasi tersebut, yang kemudian menghasilkan sesuatu (output) yang dapat diukur dengan angka atau yang dapat dipadankan dengan angka

Organisasi pembelajar memiliki dimensi dan karakteristik yang berbeda dengan organisasi yang tidak melakukan pembelajaran. Senge (1990) menyatakan bahwa organisasi pembelajar memiliki lima dimensi yaitu keahlian pribadi, model mental, berbagi visi, pembelajaran dalam tim dan berpikir sistem. Watkins dan Marsick (2003) berpendapat bahwa terdapat tujuh dimensi organisasi pembelajar yaitu continuous learning, inquiry and dialog, team learning, empowerment, embedded system, system connection, dan strategic ledership. Lebih lanjut, Marquardt (2002) menjelaskan lima model organasisasi pembelajar yang terdiri dari pembelajaran (learning), organisasi (organization), anggota organisasi (people), pengetahuan (knowledge), dan teknologi (technology). Kesemua dimensi ini diperlukan untuk memaksimalkan pembelajaran pada organisasi sehingga dapat terbentuk suatu organisasi pembelajar yang sukses dan berhasil.

Indikator variabel untuk learning organization adalah 7 dimensi yang dikemukakan oleh Marsick dan Watkins (2003). Indikator- indikator tersebut antara lain:

a. Create continuos learning capabilities: Pembelajaran di desain dalam bekerja sehingga orang dapat belajar dalam pekerjaannya; peluang disediakan untuk pendidikan dan pertumbuhan berkelanjutan.

b. Promote inquiry and dialogue: Anggota organisasi memperoleh ketrampilan productive reasoning skill untuk mengekspresikan pandangan mereka dan kapasitas untuk mendengarkan dan menanyakan pandangan orang lain ; budaya diubah untuk mendukung bertanya, umpan balik dan eksperimen.

c. Encourage collaboration and team learning: Pekerjaan dirancang untuk memanfaatkan kelompok untuk mengakses cara berpikir yang berbeda; kelompok diharapkan untuk belajar dan belajar bersama; kolaborasi dihargai dalam budaya.

d. Provide strategic leadership for learning : Model kepemimpinan, champion and support learning; kepemimpinan menggunakan pembelajaran secara strategis untuk hasil bisnis.

e. Empower people toward a collective vision: Anggota organisasi terlibat dalam pengaturan, memiliki dan menerapkan visi bersama; tanggung jawab di distribusikan dekat dengan 
INOBIS: Jurnal Inovasi Bisnis dan Manajemen Indonesia

Volume 1, Nomor 4, September 2018

Andi Hendrawan; Aneu Yulianeu; Hari Sucahyawati; Indriyani

pengambil keputusan sehingga orang- orang termotivasi untuk mempelajari apa yang mereka diminta untuk pertanggung jawabkan.

f. Connect the organization to its environment : Anggota organisasi dibantu untuk melihat pengaruh dari pekerjaan mereka pada perusahaan secara keseluruhan; Anggota organisasi mengamati lingkungan dan menggunakan informasi untuk menyesuaikan praktek kerja; organisasi terhubung dengan komunitasnya.

g. Create systems to capture and share learning : Menciptakan dan mengintegrasikan sistem teknologi, baik tinggi maupun yang rendah, untuk berbagi pembelajaran; akses disediakan; sistem diatur.

$\mathrm{Ha}_{1}$ : terdapat pengaruh pembelajaran organisasi terhadap kompetensi UMKM (Managerial skill)

$\mathrm{Ha}_{2}$ : terdapat pengaruh pembelajaran organisasi terhadap kompetensi UMKM (Conceptual skill)

$\mathrm{Ha}_{3}$ : terdapat pengaruh pembelajaran organisasi terhadap kompetensi UMKM (Human skill)

$\mathrm{Ha}_{4}$ : terdapat pengaruh pembelajaran organisasi terhadap kompetensi UMKM (Decision making skill)

$\mathrm{Ha}_{5}$ :terdapat pengaruh pembelajaran organisasi terhadap kompetensi UMKM (Time managerial skill)

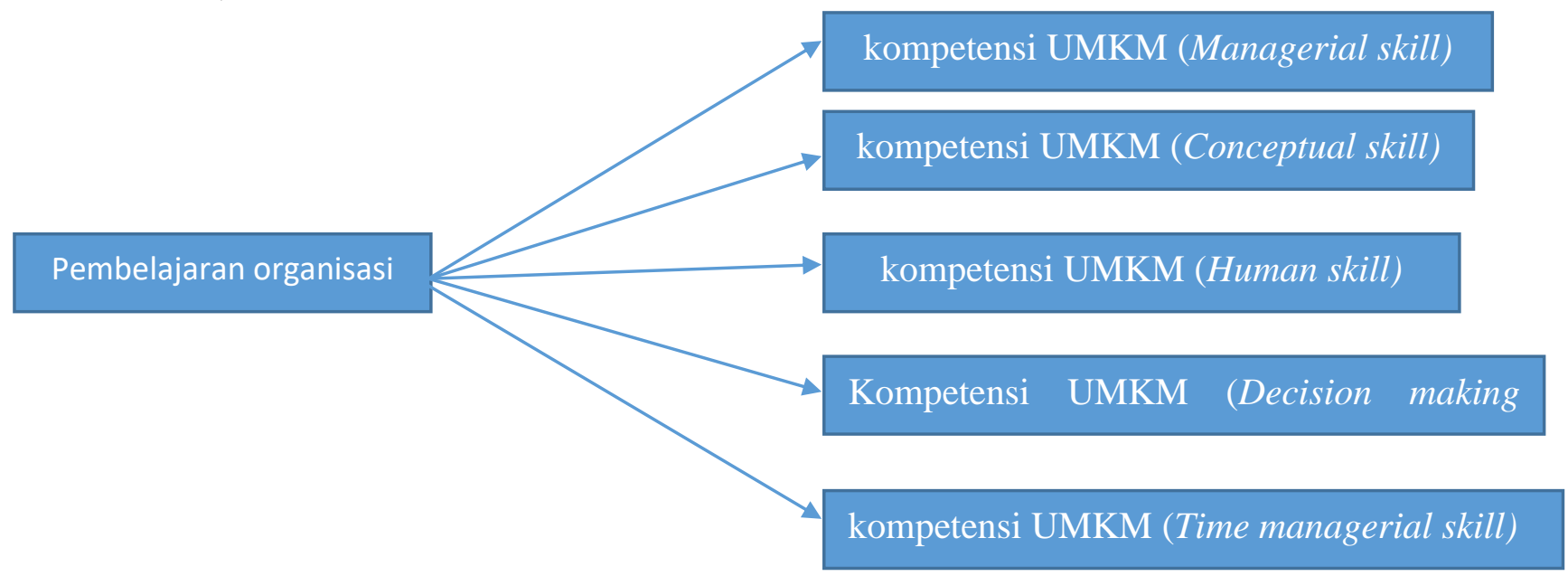

\section{Metode Penelitian}

\section{Variabel Penelitian}

Variabel yang digunakan dalam penelitian sebanyak dua variabel, yaitu variabel bebas, variabel terikat,. Di dalam penelitian yang merupakan variabel bebas adalah Pembelajaran organisasi (X1). Variabel terikatnya adalah kompetensi UMKM (Y2),

\section{Penentuan Sampel}

Teknik pengambilan sampel dalam penelitian menggunakan metode kuota random sampling, dimana mengambil sebagian dari populasi UMKM yang berjumlah 104 UMKM di 
INOBIS: Jurnal Inovasi Bisnis dan Manajemen Indonesia

Volume 1, Nomor 4, September 2018

Andi Hendrawan; Aneu Yulianeu; Hari Sucahyawati; Indriyani

Wilayah Cilacap Barat yang terdiri dari 5 Kecamatan, diambil 30 sampel deangan kuota tiap wilayah 5 UMKM..

\section{Metode Analisis Data}

Uji instrument dilakukan dengan pengujian validitas dan reliabilitas. Beberapa masalah sering muncul ketika analisis regresi digunakan. Oleh karena itu, dilakukan pengujian uji asumsi klasik berupa uji normalitas, uji linearitas dan uji multikolinieritas. Untuk menguji hipotesis dilakukan uji goodness of fit yang berupa uji koefisien determinasi total $\left(\mathrm{R}^{2} \mathrm{~m}\right)$, uji keakuratan model (uji F), dan Uji t (uji hipotesis). Kemudian dilakukan uji analisis regresi untuk menguji pengaruh variabel independen. .

\section{Hasil dan Pembahasan}

Tabel 1 Korelasi antar variabel

\begin{tabular}{|l|l|r|r|r|r|r|r|}
\hline \multicolumn{2}{|c|}{} & $\begin{array}{c}\text { Pembelaja } \\
\text { ran } \\
\text { rorganisasi }\end{array}$ & $\begin{array}{c}\text { Manageria } \\
\text { 1 skill }\end{array}$ & $\begin{array}{c}\text { Conceptual } \\
\text { skill }\end{array}$ & $\begin{array}{c}\text { Human } \\
\text { skill }\end{array}$ & $\begin{array}{c}\text { Decision } \\
\text { making } \\
\text { skill }\end{array}$ & $\begin{array}{c}\text { Time } \\
\text { managerial } \\
\text { skill }\end{array}$ \\
\hline $\begin{array}{l}\text { Pearson } \\
\text { Correlation }\end{array}$ & $\begin{array}{l}\text { PEMBELAJARA } \\
\text { N ORGANISASI }\end{array}$ & 1.000 & 0.845 & 0.654 & 0.792 & 0.861 & 0.845 \\
\cline { 2 - 8 } & Managerial skill & 0.845 & 1.000 & 0.679 & 0.831 & 0.917 & 0.952 \\
\cline { 2 - 8 } & Conceptual skill & 0.654 & 0.679 & 1.000 & 0.920 & 0.843 & 0.716 \\
\cline { 2 - 8 } & Human skill & 0.792 & 0.831 & 0.920 & 1.000 & 0.939 & 0.845 \\
\cline { 2 - 8 } & $\begin{array}{l}\text { Decision making } \\
\text { skill }\end{array}$ & 0.861 & 0.917 & 0.843 & 0.939 & 1.000 & 0.938 \\
\cline { 2 - 8 } & $\begin{array}{l}\text { Time managerial } \\
\text { skill }\end{array}$ & 0.845 & 0.952 & 0.716 & 0.845 & 0.938 & 1.000 \\
\hline
\end{tabular}

Tabel 2 hasil analisa regresi

\begin{tabular}{|c|c|c|c|c|c|c|c|}
\hline no & Independent & dependent & $\mathrm{B}$ & $\beta$ & $\mathrm{R}$ & $\mathrm{R}^{2}$ & $\mathrm{P}$ \\
\hline 1 & Managerial skill & $\begin{array}{c}\text { Pembelajaran } \\
\text { organisasi }\end{array}$ & 1.155 & 0.761 & 0.761 & 0.579 & 0.000 \\
\hline 2 & Conseptual skill & $\begin{array}{c}\text { Pembelajaran } \\
\text { organisasi }\end{array}$ & 0.917 & 0.654 & 0.654 & 0.428 & 0.000 \\
\hline 3 & Human skill & $\begin{array}{c}\text { Pembelajaran } \\
\text { organisasi }\end{array}$ & 0.834 & 0.792 & 0.792 & 0.627 & 0.000 \\
\hline 4 & $\begin{array}{c}\text { Decision making } \\
\text { skill }\end{array}$ & $\begin{array}{c}\text { Pembelajaran } \\
\text { organisasi }\end{array}$ & 1.110 & 0.861 & 0.861 & 0.742 & 0.000 \\
\hline 5 & $\begin{array}{c}\text { Time managerial } \\
\text { skill }\end{array}$ & $\begin{array}{c}\text { Pembelajaran } \\
\text { organisasi }\end{array}$ & 1.022 & 0.845 & 0.845 & 0.714 & 0.000 \\
\hline
\end{tabular}

Analisa korelasi tiap variabel dapat dtunjukan oleh tabel 1 yaitu terdapat korelasi yang signifikan antara variabel pembelajaran organisasi dengan dimensi kompetensi. Pada tabel 2 juga 
INOBIS: Jurnal Inovasi Bisnis dan Manajemen Indonesia

Volume 1, Nomor 4, September 2018

Andi Hendrawan; Aneu Yulianeu; Hari Sucahyawati; Indriyani

ditunjukan bahwa terhadap hubungan yang signifikan dengan nilai $\mathrm{P}=0,00$. Dengan nilai $\mathrm{R}$ dan $\mathrm{R}^{2}$ yang tinggi seperti yang diperlihatkan pada tabel 2, sehingga $\mathrm{H} 0$ ditolak dan menerima $\mathrm{Ha}$ yaitu terdapat pengaruh pembelajaran organisasi terhadap kompetensi UMKM. "Learning Organization adalah organisasi dimana orang mengembangkan kapasitas mereka secara terus menerus untuk menciptakan hasil yang mereka inginkan, dimana pola pikir yang luas dan baru dipelihara, dimana aspirasi kolektif dipoles, dimana orang-orang belajar tanpa henti untuk melihat segala hal secara bersama-sama (Yadi Mulyadi1 \& 1, 2016). Pola piker yang luas akan dimiliki oleh orang yang mempunyao kompetensi yang bagus, dengan komptensi yang bagus bias mengembangkan organisasi.

Menurut Dale (Njuguna, 2009),dalam (Widiastuti \& Widuri, 2012)pembelajaran organisasi dapat dicirikan sebagai proses tiga tahap yang rumit yang terdiri dari pengetahuan, diseminasi akuisisi dan implementasi bersama (interpretasi). Oleh karena itu, proses pembelajaran organisasi melibatkan pengetahuan akuisisi, distribusi, aplikasi dan terjemahan pengetahuan ini menjadi sumber daya organisasi (memori organisasi) seperti database, prosedur dan sistem yang dapat digunakan untuk meningkatkan perusahaan.

Perubahan organisasi memerlukan proses pengubahan sistem berpikir dari pola-pola lama yang sudah terinternalisasi melalui pembelajaran nilai-nilai baru kepada semua anggotanya secara konsisten. Anggota organisasi perlu iklim yang kondusif untuk merevitalisasi nilai, pengetahuan maupun ketrampilannya. Optimalisasi sumber daya manusia (SDM) sebagai modal dasar harus diikuti dengan pengembangan dan pembaruan kemampuan agar setiap anggota organisasi mampu merespon dan peka terhadap arah perubahan yang terjadi serta mendukung terjadinya pembaruan organisasi (Harvey dan Brown 2006). Untuk itu, learning organization merupakan sarana efektif untuk melakukan perubahan sistem berpikir maupun pola perilaku anggota organisasi (Shih dan Ching 2012) serta melakukan perubahan organisasi secara keseluruhan (Mulyono, Gajayana, Kresnaini, \& Gajayana, 2015). Pengembangan SDM UMKM meruapakan hal yang tidak bisa ditawar lagi, era global menuntut tingkat persaingan yang tinggi dalam bidang bisnis. Pembelajaran oragnisasi menjadi salah satu solusi dalam meningkatkan kompetensi UMKM, semakin pembelajaran oragnisasinya bagus maka kompetensi UMKM juga akan meningkat dan sebaliknya.

\section{Kesimpulan}

Berdasarakan hasil penelilitian yang dilakukan terhadap 30 UMKM di Cilacap Wilayah Barat maka dapat simpulkan sebagai berikut:

1. Terdapat pengaruh pembelajaran organisasi terhadap kompetensi UMKM (Managerial skill $)(P=0,00)$

2. Terdapat pengaruh pembelajaran organisasi terhadap kompetensi UMKM (Conceptual skill) $(P=0,00)$

3. Terdapat pengaruh pembelajaran organisasi terhadap kompetensi UMKM (Human skill) ( $P=0,00)$

4. Terdapat pengaruh pembelajaran organisasi terhadap kompetensi UMKM (Decision making skill) $(P=0,00)$

5. Terdapat pengaruh pembelajaran organisasi terhadap kompetensi UMKM (Time managerial skill) $(P=0,00)$ 
INOBIS: Jurnal Inovasi Bisnis dan Manajemen Indonesia

Volume 1, Nomor 4, September 2018

Andi Hendrawan; Aneu Yulianeu; Hari Sucahyawati; Indriyani

\section{Daftar Pustaka}

Aaker, D.A, (1989), Managing assets and skill, The kilt to asustainable competitive Advantage,California Management Review.

Alief Rakhman Setyanto DKK (2015). kajian pola pengembangan umkm di kampong batik laweyan melalui modal sosial dalam menghadapi perdagangan bebas kawasan ASEAN. JIEP-Vol. 15, No 2 November 2015 ISSN (P) 1412-2200 E-ISSN 2548-1851

Ardiana. I.D.K.R., I.A. Brahmayanti. Suhaedi. 2010. Kompetensi SDM UKM dan Pengaruhnya terhadap UKM di Surabaya. Jurnal Manajemen dan Kewirausahaan. Vol.2.12.No.1.Maret.2010

Cottam et al, (2001), Absorptive capacity, Knowledge Management and Innovation in Entrepreunerial Small Firm, International Journal and Entrepreunerial Behaviour and Research

Dooley and Sulivan, (2003), Science education in the developing world: Issues and considerations. Jurnal of Research in Science Teaching,

George Freedman (1988) Learning Productivity at Research Universities, The Journal of Higher Education

Khandekar, A., \& Anuradha Sharma. (2006). Organizational Learning and Performmance: Understanding Indian Scenario in Present Global Context. Education + Training, Vol. 48 No, 682-293. 14.

Kuncoro, Mudrajad. (2009). Dasar-dasar ekonomika pembangunan edisi 5. Yogyakarta: STIM YKPN.

Marsick, V., \& Watkins, K. (2003). Demonstrating the V of an organization's learning culture: The dimension of the learning organization questionnaire. Advances in Developing Human Resources, 5(2), 132-151.

Senge, P. (1990). The fifth discipline. New York, NY: Doubleday

Sudaryanto. (2011). The Need for ICT-Education for Manager or Agribusinessman to Increasing Farm Income : Study of Factor Influences on Computer Adoption in East Java Farm Agribusiness.International Journal of Education and Development, JEDICT, Vol 7 No 1 halm. 56-67.

Sulistyandari (2016). kompetensi sdm dan pengaruhnya terhadap kinerja umkm batik di kabupaten banyumas Performance - Vol.22 No.2 September 2016

Suryana. 2003. Kewirausahaan: Pedoman Praktis, Kiat dan Proses Menuju Sukses. Jakarta: Salemba Empat 